\title{
Sobre el uso o no de mascarillas, tan incierto como el nuevo coronavirus
}

\author{
On the use or not of masks, as uncertain as the new coronavirus
}

\author{
Jorge Marko Alessandro Benitez-Peche ${ }^{1 a}$
}

\section{Sr. Editor:}

La Organización Mundial de Salud (OMS) clasificó a la enfermedad causada por el virus SARS-CoV-2, denominada COVID-19, como pandemia el 11 de marzo del año en curso. Se sabe que este virus surgió en China en diciembre del 2019 causando un brote de neumonía de origen desconocido en ese momento detectada inicialmente en Wuhan, Hubei, China. Este virus pertenece a una gran familia de virus Ilamados coronavirus ${ }^{(1)}$. La OMS a finales de enero del 2020 declara la emergencia de salud pública, debido al aumento de muertes en China causados por este nuevo coronavirus. En el Perú, para el seis de marzo se confirmaba el primer infectado por coronavirus y que una semana antes el ministerio de salud peruano había aprobado un plan nacional ante el ingreso del SARS-CoV-2 causante de la enfermedad COVID-19.

Casi a la par que se diseminaba el virus en todo el mundo, surgieron las recomendaciones para prevenir el contagio por COVID-19, con el conocimiento previo que la transmisión del nuevo coronavirus es por vía inhalatoria o aérea y por contacto ${ }^{(2,3)}$. Es así que la principal recomendación de organismos como la OMS y el Centro de Control y Prevención de Enfermedades (CDC) de los Estados Unidos, fue la higiene de manos, una de las estrategias fundamentales de prevención ${ }^{(2,4)}$. Sin embargo, existe una serie de equipos de protección para el personal de salud que servirían durante la atención a pacientes con sospecha o confirmado de COVID-19, uno de estos son las macarillas. Aditamento que se ha difundido su uso masivo incluso en la población peruana, a causa de esta pandemia.

Al respecto, de usar mascarilla, la OMS sólo recomienda su uso si se tiene tos, estornudos o si se atiende a personas con sospecha de infección por COVID-19 (3); incluso la CDC indica que el uso de mascarillas o respiradores (N95), no es recomendado para el público en general ${ }^{(4)}$.

En el Perú, la Sociedad Peruana de Enfermedades Infecciosas y Tropicales recomienda no usar mascarillas si no se tiene síntomas (respiratorios), y los respiradores N95 solo ser reservada para el personal de salud que atenderá a personas sospechosas con COVID-19 ${ }^{(4)}$. El ministerio de salud recoge las recomendaciones anteriores, pero adiciona su uso para cuando se requiera comprar alimentos durante el aislamiento social decretado por el gobierno.

Las mascarillas quirúrgicas son aquellas que están diseñadas para evitar la diseminación de adentro hacia fuera, de microorganismos presentes en la boca, nariz o garganta de quien lo usa. Se clasifican en Tipo I y II, que dependerá de su Eficacia de Filtración Bacteriana (EFB), siendo de $95 \%$ y $98 \%$ respectivamente. Además sirven para proteger al personal de salud cuando realizan procedimientos que requieren una técnica aséptica fuera del quirófano o una medida de barrera ante salpicaduras de fluidos corporales contaminados ${ }^{(5)}$.

\footnotetext{
1. Hospital Regional Lambayeque. Chiclayo, Perú.

a. Químico farmacéutico.
} 
Las máscaras fitrantes (FFP, por sus siglas en inglés: Filtering Face Piece), de acuerdo a la norma europea establece tres clasificaciones FFP1, FFP2 y FFP3; mientras que la clasificación establecida por el Instituto Nacional de Seguridad y Salud Ocupacional americano (NIOSH, por sus siglas en inglés: National Institute for Occupational Safety and Health), es: N95, N99 y N100. Estas ofrecen una protección de afuera hacia dentro, contra patógenos de los pacientes que se transmiten a través de aerosoles (ver tabla 1$)^{(5)}$.

Tabla 1: Tipos de mascarillas filtrantes, según la clasificación europea y estadounidense.

\begin{tabular}{cccc} 
& \multicolumn{2}{c}{ Europa } & \multicolumn{2}{c}{ Estados Unidos } \\
Tipo & \% EF & Tipo & \% EF \\
FFP1 & 78 & & \\
FFP2 & 92 & & \\
& & N95 & 95 \\
FFP3 & 98 & N99 & 99 \\
& & N100 & 100 \\
\hline \hline
\end{tabular}

$\% E F=$ Eficacia de filtración mínima de partículas aéreas con tamaño menor a $0,3 \mu \mathrm{m}$.

Sin embargo, la eficacia de ambas mascarillas tanto la quirúrgica como las filtrantes son puestas a prueba en la protección ante infecciones respiratorias. Long et al., en una revisión sistemática de metanálisis, analizaron la efectividad de los respiradores N95 versus las mascarillas quirúrgicas contra la influenza y determinaron que ambas no muestran una diferencia estadísticamente significativa de prevención de la influenza confirmada por laboratorio ${ }^{(6)}$. Sin embargo, en otro estudio por Xinghuan Wang, encuentra que el no uso del respirador N95, ocasionó que la tasa de infección por el nuevo coronavirus aumente significativamente respecto a no usarlo ${ }^{(7)}$.

En un entorno de infecciones respiratorias agudas, se evaluó la efectividad de los respiradores N95 respecto de las mascarillas quirúrgicas en trabajadores de la salud, por Smith, los respiradores parecían tener una ventaja sobre las mascarillas quirúrgicas en el laboratorio, sin embargo, en un contexto clínico no se logró determinar definitivamente dicha superioridad ${ }^{(8)}$.

En el lado comunitario se promueve incluso el uso de mascarillas de tela u otro material casero, que cumplirá una protección mínima o nula para algún microorganismo presente en aerosoles, pero ante la carencia de mascarillas quirúrgicas cumplirá el objetivo de evitar el desprendimiento de grandes gotas de saliva del que lo usa y con grandes dudas de protección de contactos cercanos con pacientes en entornos clínicos.
El nuevo coronavirus SARS-CoV-2, aún es incierto en su fisiopatología, en su control y tratamiento. Ofrece un desafío a la comunidad científica para el desarrollo de tratamientos viables o la prevención a través de una vacuna tan ansiada. Lo cierto es que la prevención del COVID-19 actualmente radica en la higiene de manos y el distanciamiento social, estrategias que se complementan con el uso de, entre otros equipos de protección personal, las mascarillas. Y usadas en función al nivel de atención y el riesgo al que esté sometido el personal de salud o la población.

El uso de los respiradores N95 y las mascarillas quirúrgicas, de forma racional tanto por el personal de salud como de la población respectivamente, no debe reemplazar a la higiene de manos sino complementarla. No significa no usarlas, sino identificar el lugar y el contexto epidemiológico para que resulten efectivas. Resulta importante que los respiradores tipo N95 se reserve para el personal de salud que trabajan en la primera línea y las mascarillas quirúrgicas para el personal de salud en un entono clínico, pero sin contacto cercano a personas con sospecha de COVID-19; y para la población cuando acuda a lugares de concurrencia elevada de personas donde el brote esté en franco crecimiento.

\section{Conflicto de intereses: Ninguno}

\section{REFERENCIAS BIBLIOGRÁFICAS}

1. National Institute Health [Internet] USA. National Institute of Allergy and Infections Diseases [citado el 27 de marzo de 2020] Disponible en: https://www.niaid.nih.gov/diseases-conditions/coronaviruses

2. Sociedad Peruana de Enfermedades Infecciosas y Tropicales [Internet] Perú. SPEIT. [citado el 26 de marzo de 2020] Disponible en: https://speit. org.pe/covid-19/

3. World Health Organization [Internet]. WHO [citado el 25 de marzo de 2020] Disponible en: https://www.who.int/es/emergencies/diseases/novel-coronavirus-2019/advice-for-public/q-a-coronaviruses

4. U.S. Department of Health \& Huaman Services [Internet] USA. Centers for Disease Control and Prevention [citado el 26 de marzo de 2020] Coronavirus Disease 2019 (COVID-19) Disponible en: https://www.cdc.gov/ coronavirus/2019-ncov/infection-control/control-recommendations.html

5. Vásquez-Vizoso FL, García-García MJ, Abraira L, Campo-Pérez V. Uso de mascarillas quirúrgicas y máscaras FPP. Guía de la SOGAMP. Octubre 2015.

6. Long $\mathrm{Y}$ et al. Effectiveness of N95 respirators versus surgical masks against influenza: A systematic review and meta-analysis. J Evid Based Med. 2020; Mar 13. PMID: 32167245

7. Wang X, Pan Z, Cheng Z. Association between 2019-nCoV transmission and N95 respirator use, Journal of Hospital Infection 2020; Feb 27. PMID. 32142885

8. Smith JD, MacDougall CC, Johnstone J, Copes RA, Schwartz B, Garber GE. Effectiveness of N95 respirators versus surgical masks in protecting health care workers from acute respiratory infection: a systematic review and meta-analysis. CMAJ 2016; May 17; 188(8):567-574. PMID: 26952529 